\title{
Development of method for detection and quantification of foreign oils and fats in ghee (heat clarified milk fat) using FT NIR spectroscopy coupled with chemometric
}

\author{
KD Aparnathi, Saurabh Sharma, Bency Antony and Bhavbhuti M Mehta
}

Received: 26 September 2018 / Accepted: 24 November 2018 / Published online: 21 February 2019

(c) Indian Dairy Association (India) 2019

\begin{abstract}
Ghee is soft target for adulteration with oils/fats. Its detection by classical methods is very difficult. Therefore, study was carried out to develop FT NIR spectroscopy coupled with chemometric for detection of such adulteration. In total 20 commonly available oils and fats were selected. In development of the method, authentic samples of ghee and adulterated samples of ghee were prepared, FT NIR spectra of the samples were acquired and processed, chemometric tools were selected, prediction model was constructed and validated. The developed method predicted presence foreign oil or fat in ghee at $2.0 \%$ rate. However, identification all 20 foreign oils and fats and their quantification could be achieved when mixed at of $20 \%$ or more. The success below $20 \%$ varied depending on foreign oils/fats, rate of mixing and/or type of ghee. The method can serve as efficient and convenient analytical tool for detection and quantification of foreign oils/fats in ghee.
\end{abstract}

Keywords: Chemometrics, Ghee adulteration, NIR spectroscopy

\footnotetext{
KD Aparnathi $(\bowtie)$

Dairy Chemistry Department, SMC College of Dairy Science, Anand

Agricultural University, Anand, Gujarat, India

E-mail: kd_aparnathi@yahoo.co.in

Mobile: +919825582107

Saurabh Sharma

Near Arbuda Gas Agency, Gandhinagar, Aburoad, Rajasthan,India

(formerly with Molecular Spectroscopy-PerkinElmer, India)

Bency Antony

Kaira District Co-operative Milk Producers' Union (Amul Dairy), Gujarat, India

Bhavbhuti M Mehta

Dairy Chemistry Department, SMC College of Dairy Science, Anand Agricultural University, Anand, Gujarat, India
}

\section{Introduction}

Ghee is anhydrous milk fat, found place in India and subcontinent countries as one of the very common items in food. It is manufactured by clarification of cream or butter at a temperature of 110 to $120^{\circ} \mathrm{C}$ (Jariwala, 2014). Milk fat is undoubtedly one of the most complex of all dietary fats with variety of different fatty acids (Nurrulhidayah et al., 2013). The costly fats and oils always face a serious problem of adulteration because of the economic advantages gained by partly replacing high-priced fats with cheaper oils and fats (Quiñones-Islas et al., 2013; Lumaksoa et al., 2015). The market price of pure ghee normally 5 to 6 times higher than the commonly available oils and fats and thus making it very prone to adulteration (Nurrulhidayah et al., 2013). The most common adulterants found in ghee are vegetable oils, fat obtained by hydrogenation of vegetable oils and animal body fats. The physical texture of the oils and fats very well resembles to that of ghee, therefore, their addition in ghee cannot be detected by visual examination. Even their detection in the admixture is difficult by analysis for common physical and chemical constants (Singhal, 1980; Javidnia et al., 2013).

Fourier transform infrared (FT IR) spectroscopy is a very powerful technique for monitoring changes in the quality of food without any chemical analysis (Dupuy et al., 1996). It is a simple, quick ( $<30 \mathrm{~s}$ analysis time), non-destructive technique that provides multi-constituent analysis on virtually any matrix with levels of accuracy and precision. An immense capability of modern analytical instrumentation like infrared spectroscopy generates massive flow of data waiting for a meaningful interpretation. This task necessitates an organized data analysis by use of chemometry (Lankmayr et al., 2004). Fats and oils contain numerous components giving rise to complex spectra with overlapping bands. The most successful approach to extracting qualitative and quantitative information from such spectra is to use multivariate mathematical analysis (i.e. chemometrics tools). In respect to food fraud, chemometrics is a powerful tool used in qualitative and quantitative analysis of adulterant in samples. Reports indicate increasing use of chemometric data analyses for food fraud detection during the past 2 decades and suggest the need for their expanded use in routine testing (Moore et al., 2012). 
Near infrared (NIR) spectroscopy coupled with chemometric has been successfully applied for quality control and adulterant detection of meat and meat products, fish, chocolate, honey, wine, cakes, spirit drinks, beer and many other applications. Detection of adulteration in fats and oils using FT IR spectroscopy and multivariate analysis have been studied for virgin olive oil, extra virgin olive oil, cod liver oil, hazelnut oil, virgin coconut oil and animal body fats (Quiñones-Islas et al., 2013).

The IR spectroscopy is extensively used for determination of fat in milk since 1980s; however, potential of this highly promising analytical tool for detection of foreign oils and fats in ghee is not exploited. Even spectral characterization of ghee in MIR and NIR region was also not reported in the literature. Therefore, systematic study was undertaken in our laboratory in phased manner. In first phase, suitability of FT MIR and FT NIR spectroscopy in reflectance and transmittance mode for analysis of ghee was evaluated (Antony et al., 2016). In second phase, spectral characterization of cow and buffalo ghee in MIR region using reflectance mode (Antony et al., 2017) and in NIR region using transmittance mode (Antony et al., 2018a) was carried out. In final phase of the study attempts were made to develop IR spectroscopy based method for detection and quantification of foreign oils and fats mixed with ghee. The FT MIR spectroscopy in reflectance mode using ATR sample accessory poses some problems (Antony et al., 2018b). Finally, in this paper, method based on FT NIR spectroscopy coupled with chemometrics developed for detection and quantification of foreign oils and fats mixed in ghee is described.

\section{Materials and methods}

\section{Authentic samples of ghee}

Samples of ghee were prepared by direct cream method as described by De (2004). Thirty five samples of ghee each from cow and buffalo milk were prepared.

\section{Samples of foreign oils and foreign fats}

Samples of 15 different vegetable oils and vegetable fat were purchased from local supermarkets, whereas, sample of fish oil was obtained from a pharmacy in local market. Samples of 3 different animal body fats (lard, mutton tallow and beef tallow) were local vendors. For each of the foreign fat/oil, 4 different samples were procured.

\section{Adulterated samples of ghee}

One composite sample each of cow ghee and buffalo ghee was prepared from respective 35 authentic laboratory made samples. Then adulterated samples of ghee were prepared by blending the composite samples of ghee with foreign oil/fat using methodology as described by Quiñones-Islas et al. (2013). Each sample of foreign oil/fat was added in composite sample of cow ghee and buffalo ghee at the rate of 2, 5. 10,20 and 50 per cent ( $w /$ w).

\section{NIR spectrophotometer}

A combined FT IR spectrometer (Spectrum 400 FT IR/NIR spectrophotometer system, PerkinElmer, Inc., 940 Winter Street, Waltham, MA 02451 USA) covering complete NIR spectral ranges was used. The system equipped with room temperature infrared source, sealed and desiccated interferometer and was deuteratedtriglycine sulfate (DTGS). The operating system used was Spectrum 10, Version 4.3.2 from PerkinElmer, USA. The beam splitter was calcium fluoride $\left(\mathrm{CaF}_{2}\right)$, detector was DTGS and sample accessory was quartz cuvette.

\section{Software for chemometric analysis}

For chemometrics analysis, software package AssureID from Perkin Elmer, Inc., 940 Winter Street, Waltham, MA 02451 USA was used. The AssureID software uses two methods COMPARE and SIMCA for matching spectra.

\section{Acquisition of NIR spectra}

The NIR spectra of ghee, oils, fats and adulterated ghee were acquired using the PerkinElmer Spectrum 400 FT IR/NIR system. White light was used as a source. These spectra were subtracted against the background of air spectrum. To obtain NIR spectra, sample accessory was filled with $10 \mathrm{ml}$ of ghee, oils, fats or adulterated ghee and scanned with transmittance mode in the region of 10000-4000 cm"1 with 32 scans and resolution of $8 \mathrm{~cm}^{\prime \prime 1}$. Each sample of adulterated ghee sample was scanned in quadruplicate and their average spectra was recorded.

\section{Processing of NIR spectra}

Each set of spectra of ghee samples was then subjected batch wise to a multiplicative signal correction using the mean spectrum of the set or mean normalization. The spectrometer system interfaced to a personal computer for recording the NIR spectra. The recorded spectra of all kinds were digitized using the selected step in wavelength or wave number and stored in hard disc of the computer workstation. The absorbance of the digitized spectra was subsequently used as the spectral variables in further chemometric (multivariate) analysis.

\section{Development of prediction model for detection}

For detection and identification of foreign oil/fat in ghee from FT NIR spectra of the ghee sample by applying chemometrics (i.e. discrimination analyses), pattern recognition method suggested by Roggo et al., (2007) was used. Among two classification techniques (unsupervised and the supervised), the approach of 
supervised classification technique was adopted in the study. The classification models were developed on a training set of adulterated ghee samples with known foreign oil/fat.

From the AssureID software package for detection of adulterant, the software 'Adulterant Screen' was employed for the study. The 'Adulterant Screen' examined a sample spectrum for the presence of specific adulterants that had been selected as being of particular concern for a given sample (foreign oils and fats in this case).

\section{Development of prediction model for quantification}

For quantification of foreign oil/fat in ghee by FT NIR spectroscopic method a calibration curve of the FT NIR spectral response against known concentration foreign oil/fat in ghee was prepared for each foreign oil and fat as suggested by EAEMP (2003). Each set of spectra of adulterated ghee samples was subjected batchwise to a multiplicative signal correction using the mean spectrum of the set or mean normalization depending upon foreign oil/fat. The outliers were identified and removed when necessary by distance of sample from model. The calibration curves comprise expected (actual) values of foreign oil/fat (\%) on $x$-axis and predicted (estimated) values of the foreign oil/fat (\%) on $y$-axis.

\section{Validation of the prediction models}

Accuracy of the prediction model was validated by a method suggested by EAEMP (2003). Among the two methods (reference and true samples) suggested for the validation, the true sample method was adopted. The validation of the model was ascertained using the training set of samples prepared for the calibration (cross validation) process and also by independent set of samples prepared for purpose of validation (external validation).

\section{Results and discussion}

\section{FT NIR Spectra of ghee (Variables)}

The typical FT NIR spectra of all 35 individual samples of ghee prepared from cow milk and buffalo milk are presented in Figure 1. The NIR spectrum of cow ghee and buffalo ghee recorded between 10000 and $4500 \mathrm{~cm}^{-1}$ exhibited three broad bands in the regions of 9000 to 8000,7500 to 6150 and 6000 to $5700 \mathrm{~cm}^{\% 1}$. The NIR spectral patterns of all the samples of ghee, collected in the entire available spectral range $12000-4500 \mathrm{~cm}^{\prime \prime}$, were found to be similar across the whole wave number range along the $\mathrm{X}$-axis. However, along the absorbance at $\mathrm{Y}$ axis some minor differences were noticeable. These results are in line with our recently published report on characterization FT-NIR spectra of ghee (Antony et al., 2018a).

\section{Spectral processing}

The relevant details of pre-processing of FT NIR spectra required in the experiment for foreign oils and fats were worked out (Table
1). The result suggested that baseline correction was not required in any case of foreign oil/fat with mixed ghee samples. However, baseline correction by taking first derivative was required in the cases of cow ghee while dealing with castor oil, coconut oil, corn oil, cotton seed oil, mustard oil and beef tallow. Similarly, baseline correction by taking first derivative was required in any case of buffalo ghee while dealing with castor oil, coconut oil, corn oil, groundnut oil, mustard oil, palm kernel oil, palmolene oil, sesame oil, soybean oil, lard and fish oil. The elimination spectral preprocessing requirement in some cases was in line with the view expressed by Puente and Perston (2014). These authors reported that the default settings are tailored to the instrument and sample type and in most cases will produce good results without modification.

\section{Selection of algorithm}

The most commonly used multivariate calibration methods are principle component regression (PCR) and partial least square (PLS) (Rohman and Che Man, 2010). Therefore, study was conducted to compare performance of both of these algorithms while application in analysis of selected foreign oils and fats added in ghee. For selection of the algorithm, preliminary work was carried using all the 20 foreign oils and fats, listed for the present study. However, for detailed data on work for selection of algorithm, from 20 foreign oils and fats; 3 oils (cottonseed, groundnut and palm) and 2 animal body fats (beef tallow and lard) were selected for evaluating the performance of PCR and PLS. The performance was evaluated on the basis of per cent variance, standard error of calibration (SEC) and standard error of prediction (SEP) obtained in conducting the experiment. The data for variance (\%), SEC and SEP were obtained (Table 2). It appeared from the data that the variance cumulated by using PCR was greater in all the cases, compared the variance cumulated by using PLS. Similarly, values of SEC and SEP were smaller while using PCR compare to the corresponding values while using PLS. Thus, it was clearly evident from these results that the performance of PCR was much better compared that of the PLS.

Capuano and van Ruth (2012) opined that in chemometrics of FT IR spectra, PCA is the most widespread of among all the explorative tools. Principal component analysis (PCA) is a commonly used data compression and visualization tool, reducing a spectral data set into a small number. Therefore, findings of the present study are in line with opinion expressed by these authors. According to Quiñones-Islas et al. (2013) an important parameter of the PCR algorithm is the number of factors that are included in the calibration model. As per Ucuncuoglu et al. (2013) in chemometry, PCR is a classical and fast method for discrimination and identification analysis. Moreover, it is a basic method for soft modelling and multivariate calibration applications used to reduce the dimensionality of large data sets and eliminate redundancy by finding combinations of variables that are related 
to the major trends in the data. Therefore, PCR was selected as an algorithm for further use in the study.

\section{Prediction Model}

The prediction model is a relationship between the expected result (qualitative or quantitative) and predicted result of the experiment. The prediction models for different foreign oils/fats were worked (Table 3).In almost all the cases in cow ghee as well as buffalo ghee, the coefficient of determination was 0.99 or greater, which indicated that the regression predictions almost perfectly fit the data. The performance of the resulting prediction model for each foreign oil and fat was also evaluated in terms of SEC, SEP and variance cumulated in the experiments.

\section{SEC and SEP}

The SEC and SEP obtained in different foreign oils and fats are presented in Table 4. The difference between the respective SEC and SEP as well as ratio of the respective SEC to SEP were also worked out and presented in Table 4. The SEC and SEP values contained in the study varied depending of the type of ghee and foreign oil/fat under investigation. The SEC values ranged from 0.0462 to 1.9170 and 0.0741 to 1.7620 for cow ghee and buffalo ghee respectively. Similarly, SEP values ranged from 0.0664 to 2.1470 and 0.0985 to 2.0030 for cow ghee and buffalo ghee, respectively.

Quiñones-Islas et al. (2013) reported the models should have low value of SCE. Except a few exceptions, the SEC values were low. Thus, low values of SEC indicate that the optimal number of factors were selected for the calibration models.

As per EAEMP (2003) SEP should also be assessed in relation to the SEC, wherein, SEP and SEC should be comparable. The SEP should not be larger than 1.4 times the SEC. According to Rohman and Che Man (2011), the low values of SEP indicate the success of regression model. Quiñones-Islas et al. (2013) also suggested that high SEP indicates that the model is not adequate or effective in accurately predicting samples. Thus, SEP is an indicator for ability of the model to accurately predict unknown samples. In the present study, except a few exceptions, in most of the cases, ratio of SEP to SEC was equal to or less than 1.4. The low values of SEP in this study indicated a good correlation between predicted and actual FT NIR values of foreign oil/fat present in ghee.

\section{Variance analysis}

Table 1 Pre-processing used for FT NIR spectra of foreign oils and fats

\begin{tabular}{|c|c|c|c|}
\hline \multirow{2}{*}{$\begin{array}{c}\text { S. } \\
\text { No. }\end{array}$} & \multirow{2}{*}{ Type of ghee } & \multicolumn{2}{|c|}{ Type of pre-processing of FT NIR spectra used } \\
\hline & & None & First derivative \\
\hline 1 & Cow ghee & $\begin{array}{l}\text { - } \text { Groundnut oil } \\
\text { - } \text { Olive oil } \\
\text { - } \text { Palm oil } \\
\text { - } \text { Palm kernel oil } \\
\text { - } \text { Palmolein } \\
\text { - } \text { Palm stearin } \\
\text { - Rice bran oil } \\
\text { - Sesame oil } \\
\text { - Soybean oil } \\
\text { - Sunflower oil } \\
\text { - } \text { Vegetable fat } \\
\text { - } \text { Mutton tallow } \\
\text { - } \text { Fish oil }\end{array}$ & $\begin{array}{ll}\text { - } & \text { Castor oil } \\
\text { - } & \text { Coconut oil } \\
\text { - } & \text { Corn oil, } \\
\text { - } & \text { Cotton seed oil } \\
\text { - } & \text { Mustard oil } \\
\text { - } & \text { Beef tallow }\end{array}$ \\
\hline
\end{tabular}


Figure 1 FT NIR spectra of ghee samples
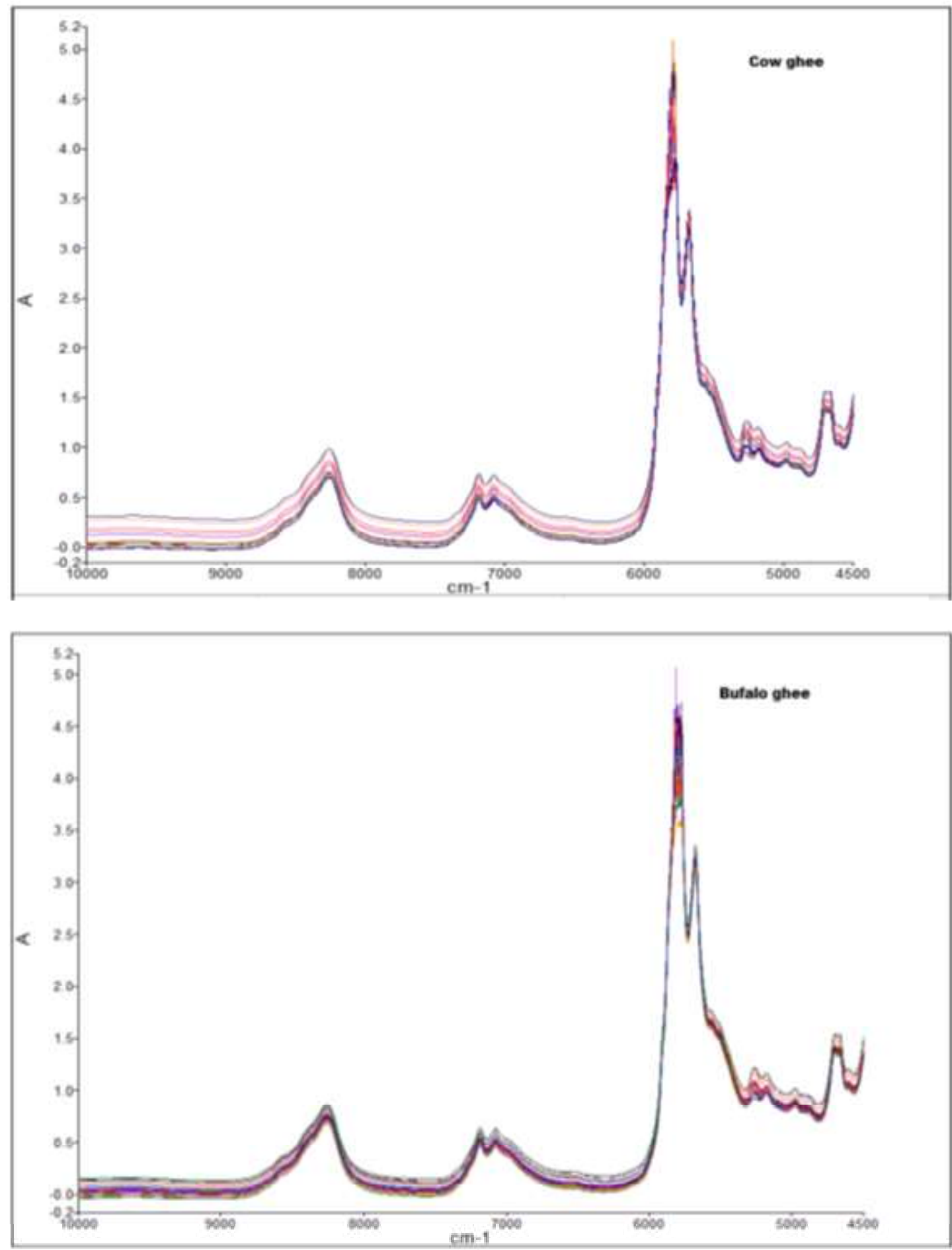

Variance analysis defines that from the variation present the spectra how much is cumulated in the experiment. The cumulated per cent variance obtained in the study with different foreign oils and fats is presented in Table 4. The cumulated per cent variance obtained in the study varied to some extent depending of the type of ghee and foreign oil/fat under investigation. However, in all the cases irrespective type of ghee or foreign oil/fat, more than 99 per cent variance could be cumulated.

Haifeng (2008) stated that the variable "factor" had a relationship with the accumulated explained variance of the spectrum, where the higher the factor is, the higher the explained spectrum variance is, which means the clearer of difference between different 
Figure 2 Validation of prediction model for identification of foreign oil/fat in ghee

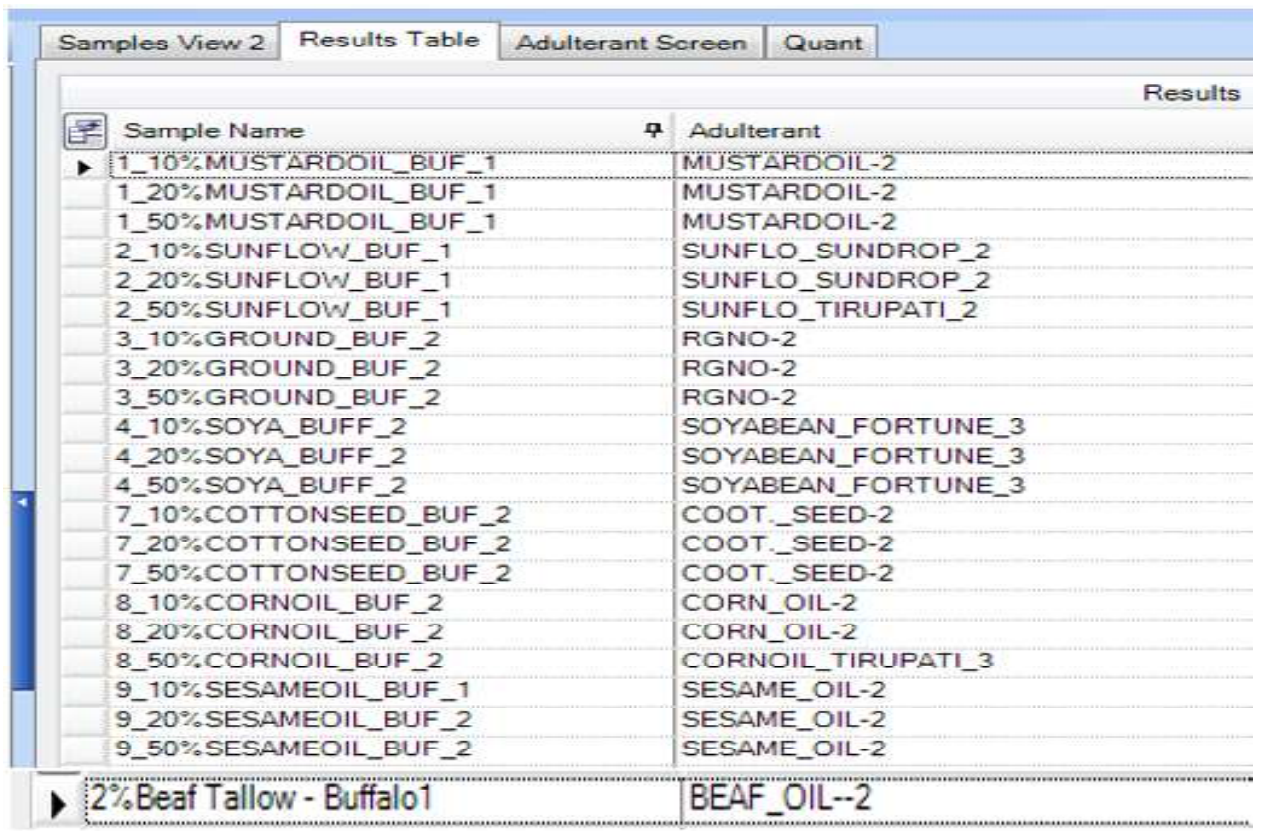

\section{(a) Cow ghee}

\begin{tabular}{|c|c|c|c|c|c|c|}
\hline & \multicolumn{2}{|c|}{ Samples View 26} & Results Table & Adulterant Screen & Quant & \\
\hline & \multicolumn{6}{|r|}{ Results } \\
\hline & 王 & \multicolumn{2}{|c|}{ Sample Name } & 4 & \multicolumn{2}{|c|}{ Adulterant } \\
\hline & & \multicolumn{3}{|c|}{$10 \_10 \%$ CASTOROIL_COW_2 } & \multicolumn{2}{|c|}{ CASTOR_OIL-2 } \\
\hline & & \multicolumn{3}{|c|}{$10 \_20 \%$ CASTOROIL_COW_2 } & \multicolumn{2}{|c|}{ CASTOR_OIL-2 } \\
\hline & & \multicolumn{3}{|c|}{$10 \_50 \%$ CASTOROIL_COW_2 } & \multicolumn{2}{|c|}{ CASTOR_OIL-2 } \\
\hline & & \multicolumn{3}{|c|}{$13 \_10 \%$ COCONUT_COW_2 } & \multicolumn{2}{|c|}{ COCONUT_OIL-2 } \\
\hline & & \multicolumn{3}{|c|}{$13 \_20 \%$ COCONUT_COW_2 } & \multicolumn{2}{|c|}{ COCONUT_OIL-2 } \\
\hline & & \multicolumn{3}{|c|}{$13 \_50 \%$ COCONUT_COW_2 } & \multicolumn{2}{|c|}{ COCONUTOIL_NIRMAL_3 } \\
\hline & & \multicolumn{3}{|c|}{14 10\%RICEBRAN_COW_2 } & \multicolumn{2}{|c|}{ RICEBRAN_FORTUNE_3 } \\
\hline & & \multicolumn{3}{|c|}{14 _20\%RICEBRAN_COW_2 } & \multicolumn{2}{|c|}{ RICEBRAN_OIL-2 } \\
\hline & & \multicolumn{3}{|c|}{14 50\%RICEBRAN_COW_2 } & \multicolumn{2}{|c|}{ RICEBRAN_OIL-2 } \\
\hline & & \multicolumn{3}{|c|}{$15 \_20 \%$ CODLIVER_COW_2 } & \multicolumn{2}{|c|}{ CODLIVER_OIL-3 } \\
\hline & & \multicolumn{3}{|c|}{ 15_50\%CODLIVER_COW_2 } & \multicolumn{2}{|c|}{ CODLIVER_OIL-3 } \\
\hline & & \multicolumn{3}{|c|}{$16 \_10 \%$ BEAFOIL_COW_2 } & \multicolumn{2}{|c|}{ BEAF_OIL--2 } \\
\hline & & \multicolumn{3}{|c|}{$16 \_20 \%$ BEAFOIL_COW_3 } & \multicolumn{2}{|c|}{ BEAF_OIL--2 } \\
\hline & & \multicolumn{3}{|c|}{$16 \_50 \%$ BEAFOIL_COW_3 } & \multicolumn{2}{|c|}{ BEAF_OIL -2 } \\
\hline & 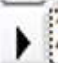 & \multicolumn{3}{|c|}{$2 \% F_{i s h} \mathrm{Oil}-\mathrm{Cow}$} & \multicolumn{2}{|c|}{ OOLIVER_OIL-2 } \\
\hline
\end{tabular}

(b) Buffalo ghee

samples. For this case, the variance analysis revealed that it was possible to obtain more than 99 per cent of the desired information.

\section{Validation of Prediction Model}

In present the study, for validation of the developed prediction models, true samples method was adopted with cross validation and external validation approaches. After completing full scale cross validation process, a few trials of external validation were conducted taking selected foreign oils and fats with the selected rate of mixing.

\section{Validation for detection and identification of foreign oils and fats mixed in ghee}

The limit of detection (LoD) and limit of identification (LoI) of various foreign oils and fats mixed in cow ghee and buffalo ghee, obtained from the cross validation study are presented in Table 5. Similarly, some specimen of results generated as reports for identification of foreign oils and fats mixed in cow ghee and buffalo during external validation process were screen sorted and same are presented in Figures 2(a) and 2(b), respectively. 
The developed prediction model was able to detect each of the foreign oils and fats included in the study, both in cow ghee as well as buffalo ghee even at level of 2.0 per cent. Similarly, the developed prediction models were able to identify each foreign oil and fat correctly, both in cow ghee as well as buffalo ghee when mixed at the rate of 20 per cent or more. However, the success in identification of the foreign oils and fats below 20 per cent rate of mixing, varied depending on foreign oils or fats, rate of their mixing with ghee and/or type of ghee.

Among the foreign oils and fats castor oil, cotton seed oil, mustard oil, rice bran oil and beef tallow could be successfully identified even as low as 2 percent level of mixing both in cow ghee as well buffalo ghee. Coconut oil, corn oil, groundnut oil, palm kernel oil, sesame oil and lard could be successfully identified at 5 percent level of mixing both in cow ghee. Similarly, corn oil, olive oil, palm kernel oil, sesame oil, soybean oil and mutton tallow could be successfully identified at 5 percent level of mixing both in buffalo ghee. Whereas, identification of palm oil, palmolein and palm stearin could be achieved at level of 10 to 20 per cent depending up on type of ghee.

Lal et al., (1998) reported that butyrorefractometer reading based test developed for detection of vegetable oils, could detect vegetable oils at a level higher than 10 per cent of milk fat, except palm oil. El-Aziz et al. (2013) evaluated the precision and sensitivity of saponification value, Reichert Meissl value, Polanske value and iodine value for detecting palm oil in milk fat.

Table 2 Comparative appraisal for performance of PCR and PLS

\begin{tabular}{|c|c|c|c|c|c|c|c|c|}
\hline \multirow[t]{2}{*}{ Sr.No. } & \multirow[t]{2}{*}{ Foreign oil/fat } & \multirow[t]{2}{*}{ Type of ghee } & \multicolumn{2}{|l|}{ SEC } & \multicolumn{2}{|l|}{ SEP } & \multicolumn{2}{|c|}{ Variance $(\%)$} \\
\hline & & & $\begin{array}{l}\text { PCR } \\
\end{array}$ & PLS & $\overline{\mathrm{PCR}}$ & PLS & $\begin{array}{l}\text { PCR } \\
\end{array}$ & PLS \\
\hline \multirow[t]{2}{*}{1.} & \multirow[t]{2}{*}{ Cottonseed oil } & Cow & 0.14 & 0.13 & 0.18 & 0.15 & 99.99 & 99.99 \\
\hline & & Buffalo & 0.18 & 0.13 & 0.15 & 0.16 & 99.99 & 99.99 \\
\hline \multirow[t]{2}{*}{2.} & \multirow[t]{2}{*}{ Groundnut oil } & Cow & 0.08 & 2.68 & 0.11 & 2.87 & 99.99 & 98.20 \\
\hline & & Buffalo & 0.54 & 0.77 & 0.75 & 1.03 & 99.93 & 99.86 \\
\hline \multirow[t]{2}{*}{3.} & \multirow[t]{2}{*}{ Palm oil } & Cow & 0.99 & 0.91 & 0.86 & 1.02 & 99.81 & 99.79 \\
\hline & & Buffalo & 1.55 & 2.62 & 1.76 & 3.16 & 99.35 & 98.29 \\
\hline \multirow[t]{2}{*}{4.} & \multirow[t]{2}{*}{ Lard } & Cow & 0.19 & 2.31 & 0.28 & 2.70 & 99.99 & 98.84 \\
\hline & & Buffalo & 0.19 & 2.08 & 0.09 & 0.16 & 99.99 & 99.99 \\
\hline \multirow[t]{3}{*}{5} & \multirow[t]{3}{*}{ Beef tallow } & Cow & 0.40 & 0.59 & 0.50 & 0.64 & 99.96 & 99.92 \\
\hline & & Buffalo & 0.19 & 0.23 & 0.15 & 0.301 & 99.99 & 99.98 \\
\hline & & Average & 0.45 & 1.25 & 0.48 & 1.22 & 99.90 & 99.48 \\
\hline
\end{tabular}

Table 3 Prediction model for quantification of foreign oils/fats

\begin{tabular}{|c|c|c|c|c|c|}
\hline & \multicolumn{2}{|l|}{ Cow ghee } & \multicolumn{2}{|l|}{ Buffalo ghee } \\
\hline \multicolumn{2}{|c|}{ Sr.No. Foreign oil/fat } & Equation & Coefficient & Equation & Coefficient \\
\hline 1 & Castor oil & $y=0.999 x-0.022$ & $\mathrm{R}^{2}=0.999$ & $y=0.998 x+0.056$ & $\mathrm{R}^{2}=0.999$ \\
\hline 2 & Coconut oil & $y=1.021 x-0.823$ & $\mathrm{R}^{2}=0.998$ & $y=0.995 x+0.173$ & $\mathrm{R}^{2}=0.999$ \\
\hline 3 & Corn oil & $y=1.016 x-0.707$ & $\mathrm{R}^{2}=0.998$ & $y=1.019 x-0.757$ & $\mathrm{R}^{2}=0.998$ \\
\hline 4 & Cotton seed oil & $y=1.000 x-0.033$ & $\mathrm{R}^{2}=1$ & $y=0.999 x+0.000$ & $\mathrm{R}^{2}=1$ \\
\hline 5 & Groundnut oil & $y=1.020 x-0.754$ & $\mathrm{R}^{2}=0.998$ & $y=1.074 x-2.584$ & $\mathrm{R}^{2}=0.992$ \\
\hline 6 & Mustard oil & $y=0.999 x-0.001$ & $\mathrm{R}^{2}=1$ & $y=1.000 x-0.052$ & $\mathrm{R}^{2}=0.999$ \\
\hline 7 & Olive oil & $y=1.000 x-0.018$ & $\mathrm{R}^{2}=1$ & $y=1.020 x-0.758$ & $\mathrm{R}^{2}=0.998$ \\
\hline 8 & Palm oil & $y=1.061 x-2.468$ & $\mathrm{R}^{2}=0.992$ & $y=1.097 x-4.997$ & $\mathrm{R}^{2}=0.967$ \\
\hline 9 & Palm kernel oil & $y=1.017 x-0.665$ & $\mathrm{R}^{2}=0.998$ & $y=0.946 x+0.028$ & $\mathrm{R}^{2}=0.995$ \\
\hline 10 & Palmolein & $y=1.110 x-5.330$ & $\mathrm{R}^{2}=0.972$ & $y=1.061 x-2.461$ & $\mathrm{R}^{2}=0.992$ \\
\hline 11 & Palm stearin & $y=1.060 x-2.421$ & $\mathrm{R}^{2}=0.991$ & $y=1.061 x-2.445$ & $\mathrm{R}^{2}=0.992$ \\
\hline 12 & Rice bran oil & $y=0.999 x+0.002$ & $\mathrm{R}^{2}=1$ & $y=1.000 x-0.027$ & $\mathrm{R}^{2}=0.999$ \\
\hline 13 & Sesame oil & $y=0.994 x-0.220$ & $\mathrm{R}^{2}=0.996$ & $y=1.018 x-0.663$ & $\mathrm{R}^{2}=0.998$ \\
\hline 14 & Soybean oil & $y=0.999 x-0.001$ & $\mathrm{R}^{2}=1$ & $y=1.016 x-0.612$ & $\mathrm{R}^{2}=0.998$ \\
\hline 15 & Sunflower oil & $y=1.061 x-2.495$ & $\mathrm{R}^{2}=0.992$ & $y=1.061 x-2.495$ & $\mathrm{R}^{2}=0.992$ \\
\hline 16 & Vegetable fat & $y=0.737 x+0.584$ & $\mathrm{R}^{2}=0.995$ & $y=0.614 x+1.480$ & $\mathrm{R}^{2}=0.992$ \\
\hline 17 & Beef tallow & $y=1.003 x-0.109$ & $\mathrm{R}^{2}=1$ & $y=1.004 x-0.048$ & $\mathrm{R}^{2}=1$ \\
\hline 18 & Mutton tallow & $y=1.060 x-2.441$ & $\mathrm{R}^{2}=0.992$ & $y=0.999 x+0.006$ & $\mathrm{R}^{2}=1$ \\
\hline 19 & Lard & $y=1.020 x-0.783$ & $\mathrm{R}^{2}=0.998$ & $y=1.061 x-2.451$ & $\mathrm{R}^{2}=0.991$ \\
\hline 20 & Fish oil & $y=0.998 x+0.012$ & $\mathrm{R}^{2}=0.999$ & $\mathrm{y}=0.995 \mathrm{x}+0.172$ & $\mathrm{R}^{2}=0.999$ \\
\hline
\end{tabular}


Table 4 SEC, SEP and cumulated variance obtained in the experiments

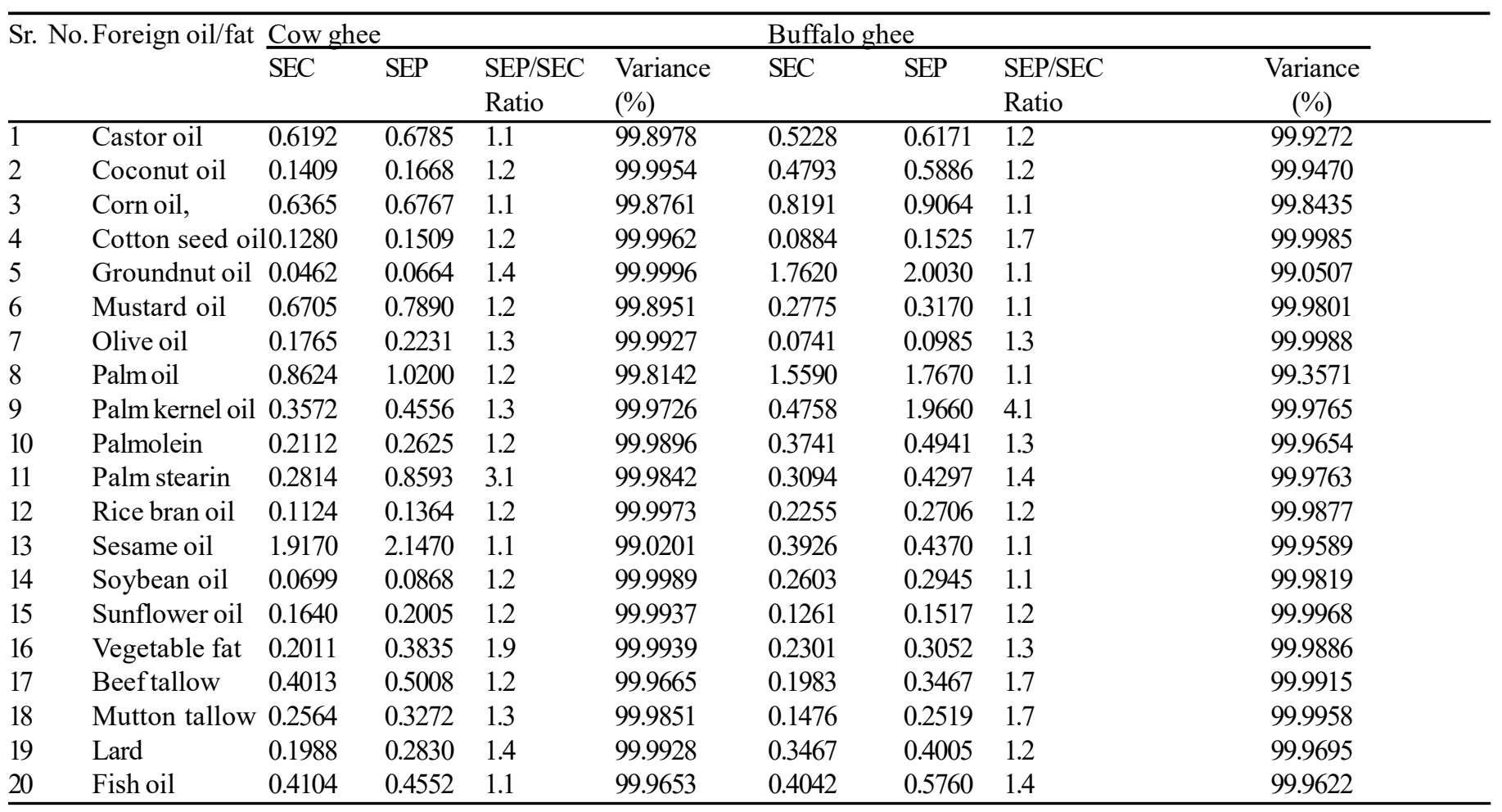

Table $5 \mathrm{LoD}$ and LoI of foreign oils and fats mixed in ghee (\%)

\begin{tabular}{|c|c|c|c|c|c|}
\hline \multirow[t]{2}{*}{ Sr. No } & \multirow[t]{2}{*}{ Foreign oil/fat } & \multicolumn{2}{|c|}{ Cow ghee } & \multicolumn{2}{|c|}{ Buffalo ghee } \\
\hline & & LoD & LoI & LoD & LoI \\
\hline 1 & Castor oil & 2 & 2 & 2 & 2 \\
\hline 2 & Coconut oil & 2 & 5 & 2 & 2 \\
\hline 3 & Corn oil & 2 & 5 & 2 & 5 \\
\hline 4 & Cotton seed oil & 2 & 2 & 2 & 2 \\
\hline 5 & Groundnut oil & 2 & 5 & 2 & 10 \\
\hline 6 & Mustard oil & 2 & 2 & 2 & 2 \\
\hline 7 & Olive oil & 2 & 2 & 2 & 5 \\
\hline 8 & Palm oil & 2 & 10 & 2 & 20 \\
\hline 9 & Palm kernel oil & 2 & 5 & 2 & 5 \\
\hline 10 & Palmolein & 2 & 20 & 2 & 10 \\
\hline 11 & Palm stearin & 2 & 10 & 2 & 10 \\
\hline 12 & Rice bran oil & 2 & 2 & 2 & 2 \\
\hline 13 & Sesame oil & 2 & 5 & 2 & 5 \\
\hline 14 & Soybean oil & 2 & 2 & 2 & 5 \\
\hline 15 & Sunflower oil & 2 & 10 & 2 & 10 \\
\hline 16 & Vegetable fat & 2 & 2 & 2 & 2 \\
\hline 17 & Beef tallow & 2 & 2 & 2 & 2 \\
\hline 18 & Mutton tallow & 2 & 10 & 2 & 5 \\
\hline 19 & Lard & 2 & 5 & 2 & 10 \\
\hline 20 & Fish oil & 2 & 2 & 2 & 2 \\
\hline
\end{tabular}

These authors also opined that these values were unable to detect the presence of palm oil in milk fat when palm oil mixed at level less than 40 per cent in milk fat. Thus, difficulties faced in detection of palm oil mixing in ghee were very well supported by the findings reported in the literature. Bellorini et al. (2005) investigated four methods (FT-IR, GC, immunoassay-based detection kits and PCR) to identify tallow (ruminant fat) and found 


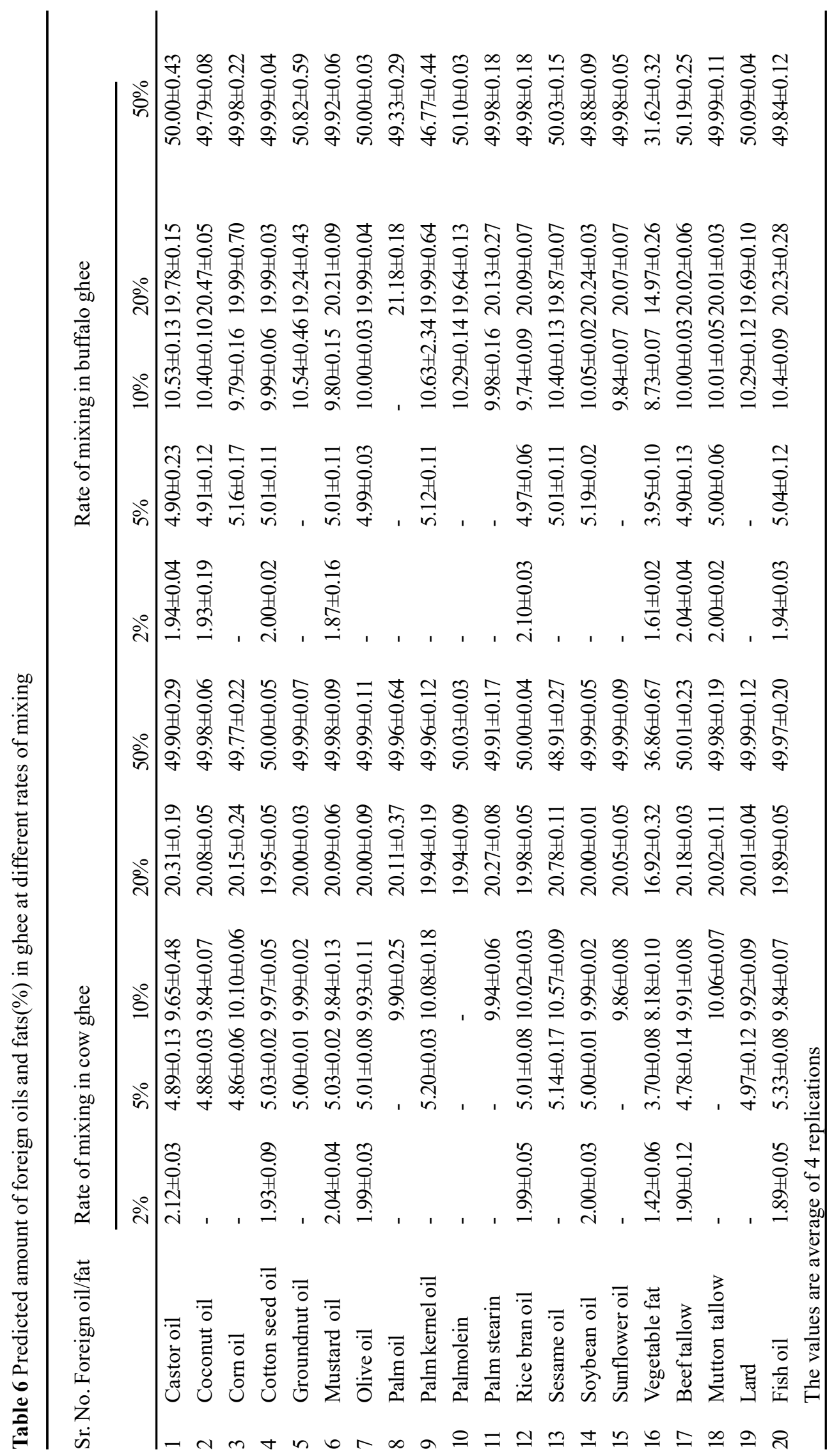




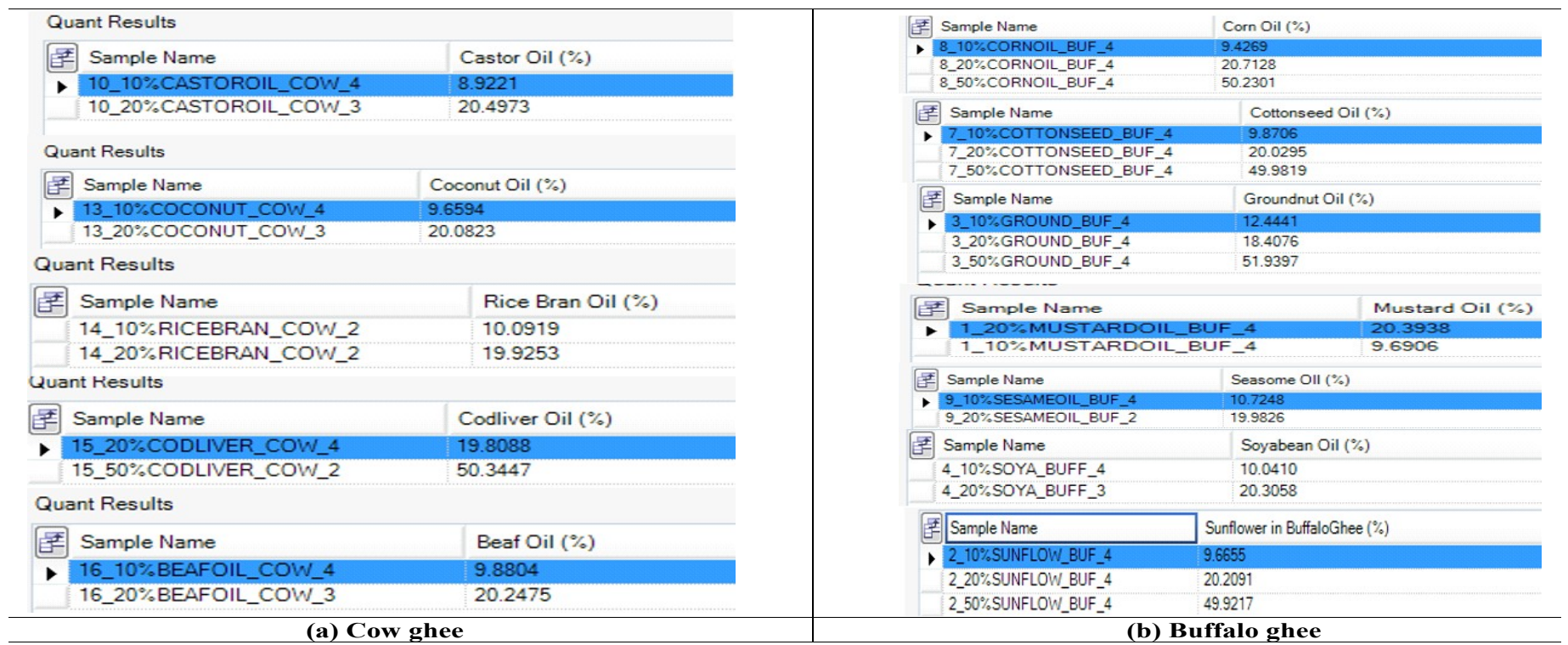

Figure 3 Validation of prediction model for quantification of foreign oil/fat in ghee

that neither of the methods proved to be suitable for detecting a specific fat, namely tallow, at concentrations of less than 10 per cent in a mixture of fats. Li et al., (2015) used FT IR spectroscopy combined with SIMCA and PLS to detect authenticity of walnut oil and amount of peanut oil, rapeseed oil, sunflower oil, and soybean oil mixed in walnut oil and reported that the method could differentiate walnut oil and other oils into separate categories with classification limit of 10 per cent.

It was evident that sensitivity and precision of the method developed in the present study is better than the methods reported in the literature for detecting number of foreign oils and fats as well as at par with the methods reported in the literature for remaining other oils and fats. The difficulties posed by palm oil palmolein and palm stearin in identification at lower rate of mixing are in line with the findings reported in the literature. Therefore, further refinement of the method required to solve this problem.

\section{Validation for quantification foreign oil/fat mixed in ghee}

The amount of foreign oils and fats predicted (\%) in cow ghee and buffalo ghee by the developed method from cross validation study are presented in Table 6. Similarly, some specimen of results generated as reports for quantification of foreign oils and fats mixed in cow ghee and buffalo during external validation process were screen sorted and some are presented in Figures 3(a) and 3(b), respectively. It is to be noted that quantification those foreign oils and fats could not be done at the rate (level) at which their correct identification was not achieved in the process of identification.
The prediction model developed for each foreign oil and fat was able to quantify the respective foreign oil and fat under examination, both in cow ghee as well as buffalo ghee. However, in quantification of foreign oils and fats, efficiency and accuracy of the developed method varied depending on foreign oils or fats, rate of their mixing with ghee and/or type of ghee. The greater variations were noticed in cases of lower rates of mixing ( 2 and 5\%), compared to that of the higher rates (20 and 50\%). In most of cases the largest differences between the predicted and the actual values of mixed foreign oils and fats were observed at addition rate of 2 per cent. On the other hand, in most of cases, the lowest differences between the predicted and the actual values of mixed foreign oils and fats were observed at addition rate of 50 per cent.

The comparison for amount of various foreign oils and fats predicted by the model and actual amount of those foreign oils and fats mixed in cow ghee and buffalo ghee revealed that the predicted values were almost equal to or very near to the actual amount mixed in almost all the cases, except vegetable fat. Therefore, the results illustrated that the calibration model developed for predicting amount of each foreign oil and fat mixed in ghee was proven realistic.

\section{Conclusions}

The finding suggested that the FT NIR spectroscopy based method couple with chemometrics developed in this study can serve as efficient and convenient analytical tool for detection, identification and quantification of foreign oils and fats mixed in cow ghee and buffalo ghee. Further work is required to refine this technique for improving its sensitivity and specificity for 
those foreign oils and fats could not be identified at a lower rates of their mixing.

\section{References}

Antony B, Sharma S, Mehta BM, Ratnam K, Aparnathi KD (2016) Comparison of transmittance and reflectance mode of FT-MIR and FT-NIR spectroscopy in application to clarified milk fat (ghee). Indian Journal of Dairy Science 69:426-431

Antony B, Sharma S, Mehta BM, Ratnam K, Aparnathi KD (2017) Study on FT-MIR Spectra of Ghee (anhydrous milk fat). British Food Journal 119: 181-189

Antony B, Sharma S, Mehta BM, Ratnam K, Aparnathi KD (2018a) Study of Fourier transform near infrared (FT-NIR) spectra of ghee (anhydrous milk fat). International Journal of Dairy Technology 71:484-490.

Antony B, Sharma S, Mehta BM, Ratnam K, Aparnathi KD (2018b) Comparative appraisal of ghee and common vegetable oils for spectral characteristics in FT-MIR reflectance spectroscopy. Journal of Food Science and Technology 55: 3632-3639

Bellorini S, Strathmann S, Baeten V, Fumiere O, Berben G, von Holst STC (2005) Discriminating animal fats and their origins: assessing the potentials of Fourier transform infrared spectroscopy, gas chromatography, immunoassay and polymerase chain reaction techniques. Anal Bioanal Chem 382: 1073

Capuano E, van Ruth SM (2012) QA: Fraud control for foods and other biomaterials by product fingerprinting. InTech Europe, University Campus STePRi, SlavkaKrautzeka 83/A, 51000 Rijeka, Croatia. pp. $112-143$

De S (2004) Outlines of Dairy Technology, 19th edition, Oxford publishing Company, New Delhi

Dupuy N, Duponchel L, Huvenne JP, Sombret B, Legrand P (1996) Classification of edible fats and oils by principal component analysis of Fourier transform infrared spectra. Food Chem 51:245

EAEMP (2003) Note for guidance on the use of near infrared spectroscopy by the pharmaceutical industry and the data requirements for new submissions and variations. The European Agency for the Evaluation of Medicinal Products, 7 Westferry Circus, Canary Wharf, London, E14 4HB, UK. (24-08-2015) assessed on http://www.ema.europa.eu/ docs/en GB/document library/Scientific guideline/2009/09/ WC500003331.pdf.

El-Aziz MA, Mahran GA, Asker AA, El-Hadad SS, Saye AF (2013) Comparative study between some methods for the detection of palm oil addition to milk fat. J Appl Sci Res 9: 786

Haifeng L (2008) Quick detection of adulterant milk by infrared spectroscopy. In Focus No.2 (2008). www.foss.dk/-/media/ 9f997bf4c9534ee8817cf5f4959d81cc.ashx (19-02-2015).

Jariwala KN (2014) Analytical techniques for the assessment of physicochemical properties of ghee. Indian J Appl Res 4: 216

Javidnia K, Parish M, Karimi S, and Hemmateenejad B (2013) Discrimination of edible oils and fats by combination of multivariate pattern recognition and FT-IR spectroscopy: A comparative study between different modeling methods. Spectrochimica Acta Part A: Mole Biomole Spectro 104: 175

Lal D, Seth R, Arora KL, Ram J (1998) Detection of vegetable oils in milk. Indian Dairyman 50:17

Lankmayr E, Mocak J, Serdt K, Balla B, Wenzl T, Bandoniene D, Gfrerer M, Wagne S (2004) Chemometrical classification of pumpkin seed oils using UV-Vis, NIR and FTIR spectra. J Biochem Biophys Methods 61: 95

Li B, Wang H, Zhao Q, Ouyang J, Wu Y (2015) Rapid detection of authenticity and adulteration of walnut oil by FTIR and fluorescence spectroscopy: A comparative study. Food Chem 181: 25

Lumaksoa, F A, Riyantoa, S., Ahmad, SAS., Rosman, AS, Yusoff, FM, Rohman A (2015) Application of chemometrics in combination with Fourier transform mid infrared spectroscopy for authentication of avocado oil. J Food Pharm Sci. 2: 12

Moore JC, Spink J, Lipp M (2012) Development and application f a database of food ingredient fraud and economically motivated adulteration from 1980 to 2010. J Food Sci 77: R118

Nurrulhidayah AF, Che Man YB, Rohman, A, Amin I, Shuhaimi M, Khatib A (2013) Authentication analysis of butter from beef fat using Fourier Transform Infrared (FTIR) spectroscopy coupled with chemometrics. Int Food Res J 20: 1383

Puente J, Perston B (2014) Quality control of olives by near-infrared spectroscopy and AssureID software. Application Note. PerkinElmer, 940 Winter Street, Waltham, MA 0245.http:// www.perkinelmer.com/CMSResources/Images/44157721APP_QC_Olives_NIR_AssureID_SW 011668_01.pdf (0403-2015)

Quiñones-Islas N, Meza-Márquez OG, Osorio-Revilla G, Gallardo-Velazque $\mathrm{T}$ (2013) Detection of adulterants in avocado oil by Mid-FTIR spectroscopy and multivariate analysis. Food Res Int 51: 148

Roggo Y, Chalus P, Maurer L, Lema-Martinez C, Edmond A, Jent N (2007) A review of near infrared spectroscopy and chemometrics in pharmaceutical technologies. J Pharma Biomed Anal 44: 683

Rohman A, Che Man YB (2010) Fourier transform infrared (FTIR) spectroscopy for analysis of extra virgin olive oil adulterated with palm oil. Food Res Int 43: 886

Rohman A, Che Man YB (2011) The use of Fourier transform mid infrared (FT-MIR) spectroscopy for detection and quantification of adulteration in virgin coconut oil. Food Chem 129: 583

Singhal OP (1980) Adulterants and methods for detection. Indian Dairyman $32: 771$

Ucuncuoglu D, Ilaslan K, Boyacý HI, Ozay DS (2013) Rapid detection of fat adulteration in bakery products using Raman and near-infrared spectroscopies. Eur Food Res Technol 237:703 